\title{
Seminario Internacional Participación politica indígena: integración e innovación política en los Andes
}

\section{Virginie Laurent}

\section{(2) OpenEdition Journals}

Edición electrónica

URL: http://journals.openedition.org/bifea/5042

DOI: 10.4000/bifea.5042

ISSN: 2076-5827

Editor

Institut Français d'Études Andines

Edición impresa

Fecha de publicación: 1 diciembre 2005

Paginación: 488-489

ISSN: 0303-7495

\section{Referencia electrónica}

Virginie Laurent, « Seminario Internacional Participación politica indígena: integración e innovación política en los Andes », Bulletin de l'Institut français d'études andines [En línea], 34 (3) | 2005, Publicado el 08 diciembre 2005, consultado el 09 diciembre 2020. URL : http://journals.openedition.org/bifea/ 5042 ; DOI : https://doi.org/10.4000/bifea.5042

\section{(c)}

Les contenus du Bulletin de l'Institut français d'études andines sont mis à disposition selon les termes de la licence Creative Commons Attribution - Pas d'Utilisation Commerciale - Pas de Modification 4.0 International. 


\section{SEMINARIO INTERNACIONAL PARTICIPACIÓN POLITICA INDÍGENA: INTEGRACIÓN E INNOVACIÓN POLÍTICA EN LOS ANDES}

Los días 24 y 25 de noviembre de 2005 tuvo lugar en Quito el Seminario Internacional Participación política indígena: integración e innovación política en los Andes, organizado por el Centro de Investigación de Movimientos Sociales del Ecuador (Cedime) y el Instituto Francés de Estudios Andinos (IFEA), con el auspicio de la Universidad Andina Simón Bolívar (Sede Ecuador). Este segundo encuentro entre estudiosos de las experiencias recientes de participación políticoelectoral indígena en Bolivia, Colombia, Ecuador y Perú hizo eco a un primer esfuerzo de trabajo común sobre esta temática, concretado dos años atrás en La Paz (Bolivia), en el marco del Seminario internacional Participación política, democracia y movimientos indígenas en Los Andes (IFEA/Programa de Investigación Estratégica en Bolivia-PIEB/Embajada de Francia). Objetivo central de organizadores y participantes — presente en ambos eventos - fue contrastar estudios de caso a nivel local, regional y/o nacional, del fenómeno se caracteriza por su manifestación a escala continental: la participación protagónica de organizaciones sociales y políticas indígenas en el escenario político. Bajo esta perspectiva las ponencias y debates se articularon, principalmente alrededor de cuatro ejes de reflexión: $1^{\circ}$ ) las características de la participación política indígena, $2^{\circ}$ ) el impacto de dicha participación en el gobierno y los diversos niveles de representación pública, $3^{\circ}$ ) su incidencia en las poblaciones indígenas mismas y $4^{\circ}$ ) las perspectivas políticas de los movimientos indígenas.

En el mes anterior a la victoria de Evo Morales en las elecciones presidenciales de Bolivia, Esteban Ticona (Universidad Mayor de San Andrés, La Paz) presentó un balance no tan positivo de la experiencia boliviana acerca de la participación indígena en política. Subrayó —con algunas excepciones alentadoras-, los efectos muchas veces devastadores de la Ley de Participación Popular - por haber sido implementada desde el Estado a favor de la descentralización promulgada en 1994-.

Pablo Ospina (Universidad Andina Simón Bolívar, Quito), propuso un análisis de caso sobre gobiernos locales —el gobierno municipal de Cotacachi y el gobierno provincial de Cotopaxibuscando evaluar su capacidad para mejorar las condiciones sociales y económicas en la sierra ecuatoriana. Esta evaluación deja entrever avances en la disminución del racismo y tratos discriminatorios hacia los indígenas, pero pocos cambios en cuanto a las políticas económicas y al control de la riqueza en el territorio. Ramón Pajuelo (Instituto de Estudios Peruanos, Lima), se interesó por los dilemas de la participación política indígena en el Perú, oponiendo las dinámicas nacionales - que apuntan a un manejo instrumental de la etnicidad desde el Estado pero se ven limitadas por la ausencia tanto de actores políticos organizados como de condiciones políticas favorables en el país - a las dinámicas locales — que atestiguan intentos de apropiación de las reformas de descentralización implementadas desde el Estado pero fracasan por la falta de preparación de los actores y su desconocimiento de los canales institucionales de participación-. 
Événements

En el marco de su investigación doctoral Lisa Glidden (University of Washington), hizo énfasis en la dinámica de la identidad y el nexo comunitario en los movimientos indígenas en el Ecuador y el Perú, diferenciando los conceptos de movilización y movimiento e insistiendo en la necesidad de rigor teórico en cuanto a la definición del movimiento social. Virginie Laurent (IFEA, Colombia), abordó la cuestión de la relación entre indianidad y espacios político-electorales en Colombia a través de la experiencia de tres años de «gobierno indígena» en Colombia, después de la elección de un indígena guambiano como gobernador del departamento del Cauca en octubre de 2000 — caso sin precedente en la historia del país—. Concedió especial atención a las dinámicas de consolidación y/o rupturas de alianzas entre varios sectores populares, indígenas y no-indígenas, generadas antes y después de dicho logro electoral. Desde la perspectiva del actor, Luis Maldonado (Escuela de Gobierno Indígena, Ecuador) se interrogó sobre los parámetros de participación política de los pueblos indígenas, cuestionando la claridad del movimiento indígena en cuanto a expectativas, formas de resolver los conflictos internos y alianzas, planteando como prioridad la búsqueda de un proyecto político propio, fundado en el paso de la protesta a la propuesta. Por último, Jorge León (Cedime, Ecuador) se interesó por el espacio político de los indígenas en los países andinos, privilegiando en su análisis el ángulo de los contextos y sistemas políticos sobre el papel y peso de los actores. Según él dichos contextos y sistemas políticos revelarían una fuerte oposición frente al conflicto desde la élite en los casos de Colombia y Perú, una mayor propensión a la negociación y la mediación en Bolivia y Ecuador.

Estas ponencias revelaron elementos comunes a las situaciones presentadas más allá de su heterogeneidad: el aumento de movilizaciones y reivindicaciones de acceso al poder en nombre de lo indio, la multiplicación de candidaturas pero también la tendencia al fraccionamiento o la precariedad de los proyectos políticos autoproclamados como indígenas. En paralelo, destacaron una serie de variables que pueden considerarse válidas para enriquecer el estudio comparativo: la proporción de la población indígena en relación con el total de habitantes, el marco jurídico e institucional en el cual se inscribe el reconocimiento de los grupos étnicos, el sistema político y el sistema electoral, el peso del Estado, el modo de tenencia de la tierra, el acceso a los recursos económicos desde el ámbito comunitario, la relación entre tierras altas y tierras bajas, el tipo de organizaciones indígenas que existen a nivel local, regional y/o nacional así como la naturaleza de sus vínculos —entre sí y con otros sectores de la sociedad-; el acceso o no a cargos de representación a escala local, regional y/o nacional y las demás formas —indígenas - de hacer política (a través de autoridades tradicionales y/o desde las organizaciones indígenas), la (auto/ hetero) percepción de la indianidad.

Por otra parte, el evento incluyó una mesa de trabajo final ¿Es posible compartir una agenda de investigaciones sobre indígenas y política en los países andinos, de modo comparativo? Prioridades y mecanismos de realización. Hacia una comunidad de investigación andina. Como respuesta los asistentes reafirmaron su voluntad de seguir indagando conjuntamente sobre el tema de la participación político-electoral indígena. Para este fin, constituyeron una Red de estudios sobre etnicidad y política en América Latina integrada inicialmente por los participantes pero que busca ampliarse para acoger otros investigadores y estudiantes interesados por esta problemática.

Virginie LAURENT 